\title{
Lithuanian Educators' Experiences of Norwegian Early Childhood Education and Care during a Short Study Trip
}

\author{
Alicja R. Sadownik*, Dziuginta Baraldsnes, Solveig Kalgraf \\ Western Norway University of Applied Sciences, Norway
}

Copyright(C2017 by authors, all rights reserved. Authors agree that this article remains permanently open access under the terms of the Creative Commons Attribution License 4.0 International License

\begin{abstract}
This paper presents an analysis of how educators from Lithuania experienced the Norwegian ECEC during a short study trip. The research results are informed by the theory of Practice Architecture [7, 8] that describes educational practices using the concepts of sayings, doings, and relatings. Sayings refer to the discursive level, doings to the level of action and work, and relatings to sociopolitical dependencies. The research was conducted during a two-day study trip of Lithuanian educators to Bergen in June 2016. The data comprised seven semi-structured, written interviews and a transcribed group discussion with seven participants. The results show that the doings experienced were strongly dependent on the transmitted sayings, which places great power in the process of framing the educational content of the study trip (lectures, presentations, and seminars). On the other hand, the experiences of the study trip were strongly dependent on the sayings, doings, and relatings that the visitors are socialized and educated with. They frame perceptions and can lead to misunderstandings. The doings and relatings experienced that agreed with the sayings, but which did not necessarily correspond to other dimensions of Lithuanian practice, led to deep reflection and even changes in institutions in the home country.
\end{abstract}

Keywords Practice Architecture, Sayings, Doings, Relatings, ECEC, Short Study Trip, Intercultural Transmission of Educational Practices

\section{Introduction}

Short study trips are increasingly popular in different professions and fields. They are supposed to facilitate learning and knowledge exchange, which is why they are so eagerly financed by international and national programs and public and private sector institutions $[22,25]$.
In this paper, we examine closely one example of a project financed by the 2009-2014 European Economic Area Financial Mechanism (EEA) within Programme No. LT08 "EEA Scholarship Programme" Study trip was one of the activities planned under the project "Modernization of the multicultural education methods in pre-school and pre-primary education," the aim of which was to modernize pre-school and education methods and means to contribute to the improvement of children's development and academic achievements regardless of cultural background.

The aim of this paper is to reconstruct the Lithuanian educators' experience of Norwegian ECEC with a special focus on multicultural education. What was possible to experience and what was perceived / experienced as well as how it was perceived during a short study trip to Norwegian ECEC institutions are the questions that this article attempts to answer.

First, the theoretical framework of Practice Architectures [7, 8] is presented. This is followed by official discourse describing Norwegian ECEC, with a focus on multicultural education. In order to provide the reader a comparative dimension - also experienced by the study trip participants - a short description of the Lithuanian ECEC is provided as well. Next, the research questions and methodology are presented. Based on our results, which follow the preceding, we argue that short study trips do not permit fostering a deep understanding of sayings-doings and relatings in the host country, because the brevity of the trip means that many of the doings and relatings are transmitted by sayings. Moreover, the visitors are socialized and educated in other meanings and practices, which, instead of fostering a deeper understanding of the host country, stimulated reflection about ECECs in the home country. In our view, this reflection is a phenomenon in which there is potential for real change in the ECECs in the visitors' home country. 


\section{Practice Architectures}

Stephem Kemmpis [7, 8] describes practice as a form of socially established, cooperative human activity in which characteristic arrangements of actions and activities (doings) are comprehensible in terms of arrangements of relevant ideas in characteristic discourses (sayings), and when people and objects involved are distributed in characteristic arrangements of relationships (relatings), and when this complex of sayings, doings, and relatings "hangs together" in a distinctive project. Educational institutions, as well as single ECECs, can be viewed as distinctive projects involving culturally, politically, professionally, and personally established configurations of sayings, doings, and relatings. These establish a practice architecture that enables and constrains preconditions for the conduct of practices. The practices appear in the form of 1) cultural-discursive arrangements (sayings), 2) material-economic arrangements in the form of daily actions (doings), and 3) social and political arrangements in the medium of power and solidarity and in the dimension of social space (relatings). In other words, every practice enacted in an ECEC unit or a classroom is the result of a practice architecture consisting of semantic (sayings), social (relatings), and physical (the material aspect of doings) spaces [7].

The cultural-discursive space (sayings) might be explained in terms of "what language or specialist discourse is appropriate for describing, interpreting, and justifying the practice" [8]. The social aspect (relatings) can be seen at work in the organization's functions, rules and roles, as well as understandings shared among different groups of teachers working at the same unit/ECEC or within the same culture $[5,8]$. The material-economic dimension is displayed in the physical space through activity and work. "Activity and work are the resources that make practice possible". [5]

\section{Practice Architecture of a Study Trip}

In the case of a study trip to a foreign country, one has to consider that the visitors were socialized and educated for a practice that was established on particular (probably other) meanings, ways of doing, and networks of power and solidarity, and these function within the culture as the (only) real, or even correct, approaches. Thus, short study trips provide an opportunity to experience practice architectures established for another set of meanings, actions, and patterns of collaborations. However, the background of discursive, action, and relational norms that a visitor comes with frames her/his experience and can limit her/his perceptions of the "new" practice and its sayings, doings, and relatings.

\section{Architecture of the Project}

The project "Modernization of multicultural education methods in pre-school and pre-primary education" aimed to modernize pre-school and pre-primary education methods and means to foster improvement in children's development and academic achievements regardless of their cultural or ethnic backgrounds. The main task was to present the "best practice" for children and families from minority backgrounds. The presentation of practices was supposed to be produced in a manual so that the practices could be applied readily in early childhood education institutions in Lithuania. Moreover, the study trip participants were obliged to lobby the relevant political groups in order to facilitate structural and institutional changes. As the goals required close teamwork and dialogue, a delegation of a small number of participants only seven - was deemed to be the optimal.

The short study trip was the part of the project during which "best practice" was supposed to be found, understood, and described to facilitate its successful implementation. However, the analysis of participants' experiences presented below shows that "finding the best practice" is a complex process that happens through continuous comparisons and reflections on ECEC practices in the home country. It was not a quick, context-less transplantation of a set of methods. One reason for this might be the way Norwegian ECEC institutions are defined and organized.

\section{Norwegian ECEC: The Official Sayings and Relatings}

Norwegian egalitarian policy stipulates that Norwegian society is inclusive, and everybody, regardless of background, is entitled to experience belonging, trust in the municipalities, and to participate in a just society without great economic or social differences [13]. The ECEC and other educational institutions play important roles in realizing this sociopolitical ideal.

The official name of the Norwegian ECEC is Barnehage, or kindergarten, and is an educational institution for children aged from one to five. Compulsory education begins at age six. Children from all social backgrounds attend kindergarten thanks to political agreement on generously subsidizing kindergartens, and $90.4 \%$ of Norwegian children aged 1-6 attend kindergartens. The foundation of Norwegian ECEC demands basic respect for every human being and promotes values that permit human beings to live together regardless of differences. These include "respect for human dignity and nature, intellectual freedom, charity, forgiveness, equality, and solidarity, values that also appear in different religions and beliefs and

\footnotetext{
${ }^{1}$ The concept of "best practice" was used in the project application form.
} 
are rooted in human rights" [15].

Moreover, ECEC institutions are obliged to collaborate with children's homes and maintain open dialogue with children's families to safeguard children's needs for care and play. "The Kindergarten shall, in collaboration and close understanding with the home, safeguard the children's need for care and play, and promote learning and formation as a basis for an all-round development" [15]. This also applies to children and families from minority, immigrant, or refugee backgrounds.

As stated in the reference [14], "There are now many ways of being Norwegian. This cultural diversity shall be reflected in kindergartens. Social, ethnic, cultural, religious, linguistic and economic differences in the population mean that children come to kindergartens with different experiences. Kindergartens shall support children on the basis of their own cultural and individual circumstances". [14]

The content of ECEC is described through the concepts of care, play, and learning. "Care is closely related to upbringing, health and security, and is also an important requisite for the development and learning of children. A lot of care is required in order to give children varied challenges and the opportunity for meaningful activities" [14].

Play is recognized as a "universal human phenomenon" with "intrinsic value" as well as children's "fundamental lifestyle, a way of learning through which children can express themselves" [14]. Learning is seen as a life-long process that, at the kindergarten age, is inseparable from play, but that is also facilitated by the staff. Thus, "children's questions must be responded to in a challenging and investigative manner, to form the basis for an active and developmentally pedagogical environment at the kindergarten. The children's own interests and questions should form the basis for learning processes and themes at kindergartens. The way in which staff respond to children's expressions in terms of body language, verbal language, feelings and social relationships will affect how they learn" [14].

In our view, what make the Norwegian ECECs unique internationally are their democratic attitude and the children's participation. "The Nordic notion of democracy as an essential feature of the good childhood requires that children experience democracy directly as an integral and consistent aspect of their daily lives at home, in school" [25] and kindergarten. Reference [25] tries to "translate" the Nordic kindergarten universe for the American reader, when discussing the issues of democracy and participation confronts the American focus on boundary setting with the Nordic modus of cooperation with children. "The 'because I said so' mentality does not exist in Nordic settings (...) A key difference is that American preschools and schools are not conceptualized as democracies, but rather, as places where students learn about democracy. It is often said that the purpose of education in America is to prepare children to participate in a democracy and to teach them to use freedom when they are adults. In contrast, Nordic people expect that children should experience democracy directly from their earliest days". [25]

This results in seeing the children as social participants who have the right to influence their own conditions according to their age and maturity $[6,14]$. Bodily and emotional expressions are understood as children's views, and children are to be supported in understanding the views of others and taking these into account. Children also have the opportunity to be active participants in planning and evaluating institutional life.

This way of thinking and practicing ECEC was new for the study trip participants, who were socialized and educated within a different model of good childcare.

\section{Lithuanian ECEC}

In Lithuania as well as in other growing economies of Central and Eastern Europe, the main discourse on good childhood regards childhood as an investment in the future [18]. That influences existing ECEC institutions and creates expectations of excellence in equipping young children with necessary "capitals" (cognitive, social and motoric) that will allow them to succeed in the future. Within the European knowledge-based economy [24] future success of the individual seems to depend on cognitive and social skills. Accordingly, the Lithuanian ECEC professional community represents a "widely shared understanding of the essential cognitive, emotional and social skills that children need to develop in their early years" [19]. However, the existing ECEC provided by private, state or municipal preschools, school-kindergartens, schools or other institutions as well as freelance educators, tends to go beyond the standards and develops a rich and competitive educational offer that can attract customers (parents interested in the best possible investment in their child's future).

The ECEC services in Lithuania are split. Children aged 0-3 attend nurseries, and children aged 3-6 kindergartens, but neither is mandatory. Children aged 6 to 7 begin compulsory pre-primary education, which is meant to contribute towards preparing for successful learning pursuant to the primary education curriculum. According to reference [23], 116,814 children aged 1-6 attended pre-school institutions in 2016, the majority of children $(101,470)$ attended nurseries and kindergartens in cities, while only 15,344 did so in villages. That creates growing inequalities that reference [19] recommends to deal with through extending the ECEC offer in rural areas.

The pre-school education is funded from the national or municipal budgets through the "student voucher" allocation system (4 hours per day or 20 hours per week). Parents make financial contributions to cover the costs of meals and learning materials; however, municipalities can 
reduce the fees families pay based on their social situation [19].

The ECEC services hire mostly highly qualified personnel. Assistants can be hired to fulfill norms required for number of workers per child. In 2016, there was 13,373 pre-school teaching staff in Lithuania. $73 \%$ of them had higher university degrees, $25.7 \%$ had higher non-university degrees, and $1.3 \%$ had completed secondary education [23].

Even though highly qualified staff is employed, the OECD [19] recommends improving staffs' relational competence. Tit is recommended that the initial (ECEC) teacher training be open for more training in real ECEC settings as it's necessary for development of important relational skills. Moreover, professional development options, including caching on teacher-child interaction is pointed out as important improvement.

Weaknesses in the relational dimensions may be understood as the result of the focus on the cognitive domain at both teacher education and institutional practice level.

\section{Methodology}

To answer our research question, namely, what the Lithuanian visitors' experience of the Norwegian ECECs was and the ways of conducting multicultural education during a short study trip, two qualitative research methods were applied. The standardized, written, open-ended interview together with a focus group interview permitted triangulating the data gathered.

The standardized, open-ended interview [3] was chosen as the research method to reconstruct participants' individual understandings of multicultural education in Norwegian kindergartens and of the institutions themselves. All informants were asked the same basic questions in the same order to increase the comparability of responses.

Since this research method has some weaknesses such as limited flexibility in relating the interview to particular individuals and circumstances, and the written form, with the standardized wording of questions that can constrain and limit the naturalness and relevance of questions and answers [3], a focus group interview was conducted three months after the study trip.

Qualitative interviews with individuals or groups are described as the most relevant when reconstructing perceptions and meanings in depth $[10,16]$. In this project, the focus group was used to capture other qualities [3] of experiences from the study trip. The group form was chosen because it frees the participants from the implicit pressure to speak continually or to please the interviewer [10], but also because of its time efficiency. The group setting also marginalizes the interviewer somewhat and allows the participants to interact. The group dynamics facilitated by the interactions provide richer, more in-depth data [9], but they also reconstruct commonalities of different social experiences [2]. The study trip was a collective experience for the group interviewed. Thus, the group interview allowed us to reconstruct to a greater degree the meanings and experiences that were shared by the group in addition to the individual experiences reconstructed from the written interview [2].

The standardized, open-ended interviews and observations were conducted on June, 22-23, 2016, and the focus group interview was held on September 26, 2016. The group interview was recorded and transcribed, and during transcription, all participant names were anonymized.

The research participants were informed about the purpose and sequence of the written interview and focus group. Participation in the research project was voluntarily and confidentiality was guaranteed. No names were used by either by the interviewers or the participants in the written interviews.

The written interviews and transcripts of group discussion were analyzed using qualitative content analysis $[12,17]$. The basic idea of qualitative content analysis is to analyze systematically open-ended and relatively unstructured texts by processing the empirical material through a category system. The category system, also known as the coding scheme, is based on the theories that underlie the development of the project. In this case, the category system is based on the Practice Architecture and includes the categories of sayings, doings, and relatings. This coding scheme is then created a priori, mirrored in the interview guide, and functions as a starting point for the interpretation of the text. The interpretation of the text is, in this case, mainly about systematizing transcripts in order to develop the codes [17].

There were seven participants of the study trip and all of them agreed to participate in the present study, in both the written open-ended interview and the focus group. All of the informants were women with higher education working in different sectors of (pre)school and/or teacher education in Lithuania. The predetermined number of participants did not permit us to reconstruct all the possible ways/qualities of experience the Norwegian practice architectures, but only those experienced by a particular group.

\section{Results}

\section{The Experienced Sayings}

The position of short-time visitors allowed the participants to perceive an array of dominant discourses that shape Norwegian ECEC, which were presented to the trip participants as "appropriate for describing, interpreting, and justifying the practice" [8] during a lecture prior to the trip and during a lecture that was a part of the visit.

The theoretical category of sayings was reconstructed in the research material through two level one categories: the "philosophy of the kindergarten" and the "paradigm of play." Each of these was operationalized with level two 
subcategories. The "philosophy of the kindergarten" was understood by the visitors through the five following subcategories:

1. meeting the child with respect for the her/him as an individual person and with respect to the family and cultural background;

2. appreciation of cultural diversity;

3. opportunities for care, play, and learning depended on the children's level of development, regardless of background;

4. parental involvement as an important aspect of ECEC functioning and integration;

5. recognition of growing up in two or more cultures simultaneously.

Table 1 presents empirical examples/quotations illustrating the subcategories presented above.

Table 1. Sayings - the philosophy of the ECEC

\begin{tabular}{|c|c|}
\hline & Theoretical category: sayings \\
\hline \multicolumn{2}{|r|}{ Subcategory level 1: The philosophy of the ECEC } \\
\hline $\begin{array}{c}\text { Subcategory } \\
\text { level } 2\end{array}$ & Example \\
\hline 1. & $\begin{array}{l}\text { "What really matters is that every child gets the personal } \\
\text { approach, it is a must to deal with each person and } \\
\text { family." [In.4] } \\
\text { "The key factor of multicultural education is the } \\
\text { individual approach and respects for the child and } \\
\text { his/her family, his/her culture and background." [In.5] }\end{array}$ \\
\hline 2. & $\begin{array}{l}\text { "The appreciation of cultural variety was something I } \\
\text { really admired. I rather expected that the Norwegians } \\
\text { would have had enough of all the immigrants." [In.3] }\end{array}$ \\
\hline 3. & $\begin{array}{l}\text { "Equal opportunities to develop, receiving assistance to } \\
\text { meet individual needs and to enjoy a happy childhood } \\
\text { regardless of the children's origine or cultures was } \\
\text { underlined by the kindergarten teachers we met." [In.7] }\end{array}$ \\
\hline 4. & $\begin{array}{l}\text { "I understood that a very important focus is put on } \\
\text { communication with parents through different activities, } \\
\text { meetings, informal discussions, celebrations, and } \\
\text { correspondence providing constant feedback on how } \\
\text { their child is doing in the kindergarten. Friendly } \\
\text { relationship between teachers and parents ensure the } \\
\text { child's security in the kindergarten and in the new } \\
\text { society, which helps them to integrate less painfully." } \\
\text { [In.5] } \\
\text { "The administration and staff seem to view } \\
\text { collaboration as an indispensable component of a } \\
\text { successful pre-school education and the child's } \\
\text { well-being. Therefore, the work with parents starts even } \\
\text { before the child starts attending the kindergarten (...) } \\
\text { The staff designs activities aimed at involving parents - } \\
\text { national holidays, stories, hiking/excursions, etc." [In.1] }\end{array}$ \\
\hline 5. & $\begin{array}{l}\text { "Multicultural education permits preserving } \\
\text { personal/cultural identity as well as developing } \\
\text { tolerance toward other persons and cultures that might } \\
\text { be unknown and/or strange to you." [In.5] } \\
\text { "This was most inspiring for me, the children's obvious } \\
\text { right to preserve the home cultural identity, to be and } \\
\text { become the one he or she feels he or she is, not what the } \\
\text { school is expecting." [In.1] }\end{array}$ \\
\hline
\end{tabular}

Within the saying of the "paradigm of play," the visitors pointed out the following:

6. play as the most important activity;

7. play as a way of becoming familiar with differences and learning respect and tolerance;

8. play as opposition to learning.

Table 2 presents the visitors utterances that refer to each of the preceding subcategories.

Table 2. Sayings - the paradigm of play

\begin{tabular}{|c|l|}
\hline \multicolumn{2}{|c|}{ Theoretical category: sayings } \\
\hline \multicolumn{2}{|c|}{ Subcategory level 1: The paradigm of play } \\
\hline $\begin{array}{c}\text { Subcategory } \\
\text { level 2 }\end{array}$ & \multicolumn{1}{|c|}{ Example } \\
\hline 6. & $\begin{array}{l}\text { "It is the play that the Norwegian pedagogues see as } \\
\text { development. They believe it is the most precious } \\
\text { activity, they say that they do a lot to preserve play and } \\
\text { support children in play." [In.2] }\end{array}$ \\
\hline 7. & $\begin{array}{l}\text { "Through playing the children become familiar with } \\
\text { different cultures and learn how to be tolerant and } \\
\text { respectful of one another regardless of their nationality } \\
\text { or color." [In.5] }\end{array}$ \\
\hline 8. & $\begin{array}{l}\text { "We were told that Norwegian parents do not want } \\
\text { their children to learn at this age; they want them to } \\
\text { enjoy their time instead." [In.4] }\end{array}$ \\
\hline
\end{tabular}

While most of the experienced sayings correspond to Norwegian discourse on ECEC, the last reported category of play as being in opposition to learning was interpreted in another paradigm of play - that combines play rather with leisure activities than the most meaningful activity in life [27]. In the Norwegian and Scandinavian context, play is not viewed as opposite to learning, but as children's way of being, and, thereby, learning [11]. The inseparable nature of play and learning is described as the Nordic holistic approach to play and learning [20], which is not equally popular in other European countries. This non-Norwegian interpretation of the study trip participants seems to stem from the strength of the visitors' own/previous/home knowledge and other well-established professional sayings.

What is interesting in the process of understanding the Norwegian sayings is the fact that the "best practice in multicultural education" that the visitors were supposed to have searched for in the form of special methods developed into a philosophy of the ECEC and its way of meeting the whole group of children and parents and not only those from minority backgrounds.

\section{The Experienced Doings}

The perceived activity and work, or the doings, regarded an array of subcategories that, in a way, confirmed and illustrated the content transmitted to the visitors during the presentations, lectures, and meetings with ECEC teachers. 
The subcategories reconstructed with the theoretical category of doings are as following:

1. omnipresent play;

2. outdoor activities;

3. children's participation;

4. food;

5. teacher professionalism.

Table 3 presents empirical examples/quotations that were analysed as relevant to four of these subcategories.

Table 3. The Experienced doings

\begin{tabular}{|c|l|}
\hline \multicolumn{2}{|c|}{ Theoretical category: doings } \\
\hline $\begin{array}{c}\text { Subcategory } \\
\text { level 1 }\end{array}$ & \multicolumn{1}{|c|}{ Example } \\
\hline 1. & $\begin{array}{l}\text { "Norwegian kindergartens view play as the most } \\
\text { important vehicle in a child's development and it is the } \\
\text { main position in the daily schedule-free play." [In.7] }\end{array}$ \\
\hline 2. & $\begin{array}{l}\text { "They spend a lot of time outside in Norway in all } \\
\text { kinds of weather. The children play outside at least two } \\
\text { hours every day...This routine takes up a lot of the day. } \\
\text { The outdoor play or walk..." [In.2] } \\
\text { "Well, they need to go out in the rain and have good } \\
\text { clothes otherwise they would never go out." [In.1] }\end{array}$ \\
\hline 3. & $\begin{array}{l}\text { "The kids have an opportunity to choose the activities } \\
\text { they want to do and the things they want to use." [In.5] } \\
\text { "When we were there the teacher just asked the } \\
\text { children what they wanted to do. They wanted to go } \\
\text { out, so they did, even though the rest of the group was } \\
\text { still inside." [In.1] }\end{array}$ \\
\hline 4. & $\begin{array}{l}\text { "What shocked us really was that the children don't get } \\
\text { a hot meal during the day, and the climate is rather } \\
\text { cold. Or in some kindergartens they get one warm } \\
\text { meal...This was very different from what we know as a } \\
\text { proper nutrition." [In.1] }\end{array}$ \\
\hline
\end{tabular}

What we find interesting in these quotations is the combination of sayings and doings in the subcategory of omnipresent play. In the first part of the utterance, "Norwegian kindergartens view play as the most important," refers to the cultural-discursive level, while the latter part, "it is the main position in the daily schedule," refers to the sphere of doings. Many sociology theories emphasize that people and groups do things out of their best understandings of various phenomena, but we believe that underlying this connection in the group interview is the marking of cultural distance. "They do what they do, because they think this and that" may be seen as a reconstruction of strange/other sayings and doings in a respectful way. In Lithuanian kindergartens, the daily routines are organized in a more structured way with the adults taking the leading roles.

This could be why the participation of children in the Norwegian kindergartens was seen only one dimensionally. According to Norwegian literature and law, children participate by co-deciding about routines and equipment to buy, expressing their feelings, being observed in play (which often leads to purchasing equipment to stimulate their play), and choosing their activities. The visitors perceived only the last dimension of the children's participation, which could have stemmed from the fact that the subject of children's participation, a unique dimension of Norwegian ECEC, was not presented or discussed thoroughly enough. In other words, the study trip participants did not receive enough sayings to perceive all the aspects of the children's participation.

The next aspect, the outdoor doings in all weather conditions, is related by the informants to the climate (not ECEC to values, beliefs or practices). Briefly, the study trip participants understood that people had to adjust to the cold, rainy climate with good clothes, otherwise they would never get outdoors. This reflection combines some Norwegian cultural sayings with the ongoing doings, which, in our view, again marks the strange character (for the visitors) of the ongoing practices. As they come from a milder climate, this level of adjustment to all weather conditions is unnecessary.

Food and meals usually surprising or even shocking when different cultures meet [4]. In this case, the cold-lunch tradition was met by a group socialized with a warm-lunch tradition.

The fifth subcategory, teacher professionalism, developed during the analysis was seen in a couple of different ways, which is why it was analysed separately. Teacher professionalism (a level one subcategory) was seen through five different aspects (level two categories), as follows:

1. facilitating not overtaking;

2. being available to the children;

3. enthusiasm and curiosity;

4. knowledge about the children's backgrounds;

5. professional freedom.

Table 4 presents empirical examples of how the different aspects of teacher professionalism were understood by the study trip participants.

The perceived doings related to teacher professionalism were understood and perceived by the study trip participants as they are in Norway. Our first reaction when looking at the data was surprise, because the informants were thinking according to the Norwegian discourse on ECEC teacher professionalism. This prompted us to reflect on what might be the reason behind this. One reason could have been that this subject was presented at the conference and lecture, which meant that the study trip participants had received an overview of the ongoing sayings of teacher professionalism and felt "obligated" to answer according the content that was presented (in order to show respect and loyalty to the hosts).

On the other hand, it might be a sign that the Lithuanian educators can distance themselves from their professional and institutional practice, which does not necessarily seem to them as an ideal one. Instead, it might be organized and performed as it is because of the available resources (one 
teacher per 21 children) and a bureaucracy that demands detailed curriculums, programs and plans that do not permit the teacher to consider the children's individual needs and interests.

Table 4. Doings: Teacher professionalism

\begin{tabular}{|c|c|}
\hline \multicolumn{2}{|r|}{ Theoretical category: doings } \\
\hline \multicolumn{2}{|r|}{ Subcategory level 1: Teacher professionalism } \\
\hline $\begin{array}{l}\text { Subcategory } \\
\quad \text { level } 2\end{array}$ & Example \\
\hline 1. & $\begin{array}{l}\text { "What really surprised me was that the teachers were } \\
\text { kind of behind all the activities; they were facilitating } \\
\text { children. It means their main work was to organize and } \\
\text { plan in advance, not to overtake and lead the group in the } \\
\text { here and now." [In.3] }\end{array}$ \\
\hline 2. & $\begin{array}{l}\text { "The teachers were present, always ready to take care of } \\
\text { something, help, and answer a question." [In.1] }\end{array}$ \\
\hline 3. & $\begin{array}{l}\text { "The teachers we met are really enthusiastic and } \\
\text { easy-going with children [In. 2]. } \\
\text { "The teachers are really interested in how the children } \\
\text { feel in different situations." [In.7] }\end{array}$ \\
\hline 4. & $\begin{array}{l}\text { "They have a lot of knowledge about the children's } \\
\text { cultural backgrounds and are really interested (...) The } \\
\text { teachers do their best to individualize the educational } \\
\text { content in accordance with the child's cultural } \\
\text { experience." [In.3] }\end{array}$ \\
\hline 5. & $\begin{array}{l}\text { "(...) the teachers enjoy more freedom in choosing what } \\
\text { to do and when to do it, although they do follow some } \\
\text { strategy and hopefully achieve set goals. They seem to be } \\
\text { more sensitive to the children's immediate needs and } \\
\text { wishes. There is more consideration given to the child, } \\
\text { not to the teacher's plan, which can be easily modified or } \\
\text { postponed." [In.1] }\end{array}$ \\
\hline
\end{tabular}

\section{The Experienced - Relatings}

When it comes to relatings, only those within a kindergarten and between kindergarten and the children's families were distinguished in the research material. The reconstructed dimensions of relatings referred to:

1. relationships among staff;

2. relationships among staff and children;

3. relationships among children;

4. ECEC cooperation with parents.

Table 5 presents empirical examples/quotations illustrating the subcategories presented above.

Within the first subcategory of relatings (relationships among staff), the non-hierarchical organizational structure of the working team was mentioned. The team usually consists of one pedagogue, who is the pedagogical leader, and two assistants, who do not have to have any qualifications to work with children. Although there are differences in qualifications and positions among the team members, the visitors pointed out the team spirit, the relaxed atmosphere, and the friendly relationships among the staff. The differences in position and qualification did not lead to great differences in work tasks [1], the accent was placed on the collective dimension of the team. Although in Norway this is criticized as blocking the development of quality, it was perceived as very positive by the Lithuanian visitors, who are accustomed to clear hierarchies based on qualifications and positions. As one of the participants put it, "The atmosphere in the kindergartens we visited seemed very warm and friendly. I didn't feel any hierarchical distance among administrators, teachers, or assistants like there is in Lithuania when people with different qualifications meet." [In.3] Another informant pointed out the influence that the friendly atmosphere had on the children, "I enjoyed seeing the very warm, friendly relationships among teachers and other staff. The atmosphere was welcoming and relaxed, which also impacts the children's behavior." [In.5]

Table 5. Relatings

\begin{tabular}{|c|l|}
\hline \multicolumn{2}{|c|}{ Theoretical category: relatings } \\
\hline \multicolumn{2}{|c|}{ Subcategory level 1: Teacher professionalism } \\
\hline $\begin{array}{c}\text { Subcategory } \\
\text { level } 2\end{array}$ & \multicolumn{1}{|c|}{ Example } \\
\hline 1. & $\begin{array}{l}\text { "The atmosphere in the kindergartens we visited seemed } \\
\text { very warm and friendly. I didn't feel any hierarchical } \\
\text { distance among administrators, teachers, or assistants } \\
\text { like there is in Lithuania when people with different } \\
\text { qualifications meet." [In.3] }\end{array}$ \\
\hline 2. & $\begin{array}{l}\text { "continuous individual attention to the child," [In. 7] } \\
\text { "Norwegian teacher being led by the child and his/her } \\
\text { needs and achievements," [In. 3] }\end{array}$ \\
\hline 3. & $\begin{array}{l}\text { "The atmosphere is welcoming and relaxed, which also } \\
\text { impacts the child's behavior." [In.5] } \\
\text { "The children play with each other and thereby discover } \\
\text { differences among them, but the play allows them to } \\
\text { learn about it as something very, very natural, as a natural } \\
\text { aspect of the world, of society." [In.6] }\end{array}$ \\
\hline 4. & $\begin{array}{l}\text { "They do their best to involve parents in the educational } \\
\text { process and to promote cooperation based on mutual } \\
\text { respect and understanding." [In. 7] } \\
\text { “...the work with parents starts even before the child } \\
\text { begins attending kindergarten (information booklets and } \\
\text { direct contact) and continues throughout the child's } \\
\text { attendance." [In. 1] }\end{array}$ \\
\hline
\end{tabular}

Within the second subcategory of relatings (relationships among staff and children), the child-centered character of the Norwegian ECEC was underscored. The "continuous individual attention to the child," [In. 7] that was basically about the "Norwegian teacher being led by the child and his/her needs and achievements," [In. 3] and not by plans, programs, or methods that the teacher is obliged to follow," as was mentioned with regard to teacher professionalism. The focus on each child and the children 
as a group was referred to by the visitors as "a holistic approach to the child while maintaining dialogue with him/her regardless of the age or nationality of the child." [In. 5]

These impacts the relationships the children develop with each other. While this was not the subject of any of the lectures or presentations for the participants, it was possible for them to perceive this. "The atmosphere is welcoming and relaxed, which also impacts the child's behavior." [In.5]. This includes how the atmosphere affects to a great degree the situation of the children from minority backgrounds and those with special needs. These children are "... simply 'taken' to the group and everybody else is with him/her from the start." [In. 4] "The children play with each other and thereby discover differences among them, but the play allows them to learn about it as something very, very natural, as a natural aspect of the world, of society." [In. 6]

The last aspect of the relatings refers to parental cooperation that is an inseparable part of daily ECEC functioning. "The pedagogue communicates with the parents on a daily basis," [In. 2] which was seen as important "for the sake of the child and his/her smooth integration into the community." [In. 5]

What differs from Lithuanian practice is that "...the work with parents starts even before the child begins attending kindergarten (information booklets and direct contact) and continues throughout the child's attendance." [In. 1] However different the Norwegian system is at the practical level, it is, again, in line with the participants' ideals and beliefs. This seems to render the new practice in a positive light for the participants.

Analogically, with parental involvement in the kindergarten's activities through less formal events like "celebrations and trips" [In.5], "This really helps us to get the parents more involved in the kindergarten. When it's only formal, the distance seems to be greater...." [In.6] The teacher's engagement is seen as important for parental cooperation and as real among the ECEC teachers the participants met. "They do their best to involve parents in the educational process and to promote cooperation based on mutual respect and understanding." [In. 7]

\section{Summary}

This paper analyzes Lithuanian participant's experiences during a short study trip using the main categories of Practice Architecture theory $[6,7]$ that are sayings, doings, and relatings.

This theoretical toolkit allowed us to analyze different dimensions of the study trip and the experiences of the participants. The broad perspective on the activity of the study trip revealed that the aim of the study trip was "finding the best practice." This was identified originally by the study trip participants as a method or set of methods that could be easily "transplanted" to Lithuania, but it was extended to include deep reflections on ECEC values, parental cooperation, relationships among the entire group of adults and children, and teacher professionalism. This was rooted in the holistic character of Norwegian kindergartens that do not follow special methods, but was constructed on humanist values and pedagogical freedom to allow teachers to respond to and fulfill children's needs for care, play, and formation.

The experiences of different aspects of the new practice are related to the architecture of the study trip, which often consists of lectures and presentations and visits to real institutions. Our research material showed that the participants were dependent on the transmitted sayings in order to observe certain dimension of the doings. There were material aspects connected to actions and activities that were perceived by the study trip participants that were not mentioned in the theoretical presentations (sayings). However, since the sayings transmitted seemed to frame the experience of the doings, herein lies great power in choosing the content of the lectures, presentations, and other materials presented to study trip participants.

However, not all of the presented and perceived sayings-doings combinations were experienced as inspiring or interesting. Some of them were strange. In our analysis, these were the ones that did not correspond to the visitors' practical background on the levels of discourse, theory, ideas, or practice. When there were differences at the level of doings, some of the Norwegian solutions were accepted, but then it turned out that these Norwegian practices are in agreement with professional beliefs and needs held by the Lithuanian educators and OECD in Lithuania. In these instances, the differences in the "practiced practices" were about available resources rather than culture.

Nevertheless, the cultural and professional background of the visitors played a great role, especially in experience combinations of sayings and doings that were dissimilar with Lithuanian ones. In such cases, background can even lead to a different interpretation of the content transmitted, as was the case with the holistic approach to play.

However, experiencing another way of practicing ECEC during the short study trip was limited and risky. One of the significant limitations is the duration of the study trip, which was only two days to visit both the ECEC and the university college. The program of the study trip was compact, which did not allow the participants to become a part of the practice architectures. Their experiences are in a way based on "sayings" transmitted to them by the hosts. Even the "doings" and "relatings" were partly told to the study trip participants.

Another disadvantage related to the study is that it was conducted with 7 informants, coinciding with the number of the study trip participants. This is the reason for our uncertainty about data saturation. Nevertheless, the study trip for the participating group was a source of important 
inspiration and reflection. This was unrelated to the kindergartens visited, but rather to those in the home country. It related especially to the dimensions of practice that were in agreement with Lithuanian sayings that for some reasons, primarily economic, were not practiced. These reflections, in our opinion, hold a strong potential to initiate change. These kinds of reflections based on the teacher professionalism experienced could lead to work on changes within Lithuanian ECEC and preschool education that we - the researchers - were informed about by the study trip participants and the representatives of the Lithuanian Ministry of Education.

\section{REFERENCES}

[1] W. Aasen. Teamledelse i barnehagen, Fagbokforlaget, Bergen, 2012.

[2] R. Bohnsack. Documentary method and group discussions, in Bohnsack, Ralf, Pfaff, Nicolle, Weller, Wivian (Ed.): Qualitative analysis and documentary method in international educational research, B. Budrich, Opladen, 99-124, 2010.

[3] L. Cohen, L. Manion, K. Morrison. Research Methods in Education (6th edition), Routledge Taylor \& Francis Group, London and New York, 2007.

[4] Encykolpedia of Food and Culture, Charles Scribner's Sons, New York, 2004.

[5] V.A. Goodyear, A. Casey \& D. Kirk. Practice architectures and sustainable curriculum renewal, Journal of Curriculum Studies. DOI: 10.1080/00220272.2016.1149223, 2016.

[6] L.T. Grindheim. Barnefellesskap som demokratisk danningsarena, Nordic Early Childhood Education Research. Vol 4, No 2, 2011.

[7] S. Kemmis. Phronesis, Experience, and the Primacy of Praxis, in Kinsella, Elizabeth Anne, Pitman, Allan (Ed.): Phronēsis as professional knowledge: Practical wisdom in the professions, Publisher: Sense, 147-162, 2012.

[8] S. Kemmis, J. Wilkinson, C. Edwards-Groves, I. Hardy, P. Grootenboer, L. Bristol. Changing Practices, Changing Education, Springer Singapore Heidelberg New York Dordrecht London, 2014.

[9] V.E. Kress \& M.F. Shoffer. Focus Groups: A Practical and Applied Research Approach for Counselors, Journal of Counselling and Development, Vol. 85, Issue 2, 189-195, 2007.

[10] R.A. Krueger \& M.A. Casey. Focus Groups. A Practical Guide for Applied Research (3rd Edition). Thousand Oaks, CA, Sage Publications, 2000.

[11] O.F. Lillemyr. Kompetanseoppbygging for FOU-basert undervisning og forskeropplæring, Et invitert innlegg på et arbeidsseminar om FOU-arbeid i lærerutdanningen, Sundvollen, 19. og 20. april 1994.
[12] P. Mayring. Qualitative Content Analysis, Qualitative Social Research, Vol. 1, No. 2, Art. 20, 2000.

[13] Ministry of Children, Equality and Inclusion. En helhetlig integreringspolitikk [A Holistic Integration Policy]. Oslo: Ministry of Children, Equality and Inclusion 2012-2013, Oslo, Ministry of Children, Equality and Inclusion, 2012.

[14] Norwegian Ministry of Education and Research. Framework plan for the Content and Tasks of Kindergartens, Oslo, Norwegian Ministry of Education and Research, 2011.

[15] Norwegian Ministry of Education and Research. Act no. 64 of June 2005 relating to Kindergartens (the Kindergarten Act), Oslo, Norwegian Ministry of Education and Research, 2005.

[16] D.L. Morgan. Focus Groups as Qualitative Research, SAGE Research Methods, 1996.

[17] K.A. Neuendorf. The Content Analysis Guidebook, Sage Publications, Thousand Oaks, London, New Delhi, 2002.

[18] Obrebska, M. Semantyka dziecinstwa: od nieobecnosci do odrebnosci. Studia Kulturoznawcze Issue 1, 49-57, 2011.

[19] OECD, Education in Lithuania, Reviews on National Policies for Education, Paris, OECD Publishing, 2017. http://dx.doi.org/10.1787/9789264281486-en

[20] I. Pramling-Samuelsson. Teaching and Learning in Preschool and the first years of elementary school in Sweden, in J. Einarsdottir, J.T. Wagner, (ed). Nordic Childhoods and Early Education: Philosophy, Research, Policy and Practice in Denmark, Finland, Iceland, Norway, and Sweden, Greenwich, IAP, 101-132, 2006.

[21] I. Pramling-Samuelsson, M.A. Carlson. The Playing Learning Child. Towards a Pedagogy of Early Childhood, Scandinavian Journal of Educational Research Vol. 6, Issue 52, 623-641, 2008

[22] N. Santoro, J. Major. Learning to be a culturally responsive teacher through international study trips: transformation or tourism? Teaching Education, Vol. 23, Issue 3, 2012.

[23] Statistics of Lithuania. Available at: https://osp.stat.gov.lt/statistiniu-rodikliu-analize?theme=all \#/, 2017.

[24] The Lisbon European Council-An Agenda of Economic and Social Renewal for Europe; European Council: Brussels, Belgium, 2000.

[25] J.T. Wagner. An Outsider Perspective: Childhoods and Early Education in Nordic countries, in J. Einarsdottir, J.T. Wagner (ed). Nordic Childhoods and Early Education: Philosophy, Research, Policy and Practice in Denmark, Finland, Iceland, Norway, and Sweden, Greenwich, IAP, 289-306, 2006.

[26] L.M. Walters, B. Garii, T. Walters. Learning globally, teaching locally: incorporating international exchange and intercultural learning into pre - service teacher training, Intercultural Education, Vol. 20, Issue 1, 151-S158, 2009.

[27] M. Øksnes. Lekens flertydighet. Om barns lek i en institusjonalisert barndom. Oslo, Cappelen Damm Akademisk Forlag, 2013. 